\title{
Pathway Analysis of a Zero-Emission Transition in the Nordic-Baltic Region
}

\author{
Peter D. Lund ${ }^{1, *}{ }^{\mathbb{D}}$, Klaus Skytte ${ }^{2}$, Simon Bolwig ${ }^{2}{ }^{\oplus}$, Torjus Folsland Bolkesjö ${ }^{3}$, \\ Claire Bergaentzlé ${ }^{2}{ }^{\oplus}$, Philipp Andreas Gunkel ${ }^{2}$, Jon Gustav Kirkerud ${ }^{3}$, Antje Klitkou ${ }^{4}{ }^{\oplus}$, \\ Hardi Koduvere ${ }^{5}$, Armands Gravelsins ${ }^{6}$, Dagnija Blumberga ${ }^{6}$ and Lennart Söder ${ }^{7}$ \\ 1 Department of Applied Physics, School of Science, Aalto University, 02150 Espoo, Finland \\ 2 Department of Management Engineering, Technical University of Denmark (DTU), \\ 2800 Kongens Lyngby, Denmark \\ 3 Faculty of Environmental Sciences and Natural Resource Management, Norwegian University of Life \\ Sciences (NMBU), 1432 Aas, Norway \\ 4 Nordic Institute for Studies in Innovation, Research and Education (NIFU), 0608 Oslo, Norway \\ 5 Department of Electrical Power Engineering and Mechatronics, Tallinn University of Technology (TalTech), \\ 19086 Tallinn, Estonia \\ 6 Institute of Energy Systems and Environment, Riga Technical University (RTU), 1048 Riga, Latvia \\ 7 Division of Electric Power and Energy Systems, Royal Institute of Technology (KTH), \\ 10444 Stockholm, Sweden \\ * Correspondence: peter.lund@aalto.fi
}

Received: 30 June 2019; Accepted: 25 August 2019; Published: 29 August 2019

\begin{abstract}
A zero-emission pathway for the Nordic and Baltic region in Europe is described based on the comprehensive policy and scenario analyses, accompanied by energy system modelling. The analyses show that a least-cost strategy would massively employ renewable energy, particularly in the power sector. Through strong coupling across energy sectors and countries, electricity would play a central role in the decarbonization of the main energy sectors. In particular power-to-heat conversion, where heat storage appears important in addition to existing hydropower. Technical and regulatory barriers in front of increased sector coupling and flexibility were identified, and policy measures are proposed to overcome these. In addition to a high carbon price, dynamic tariffs and taxation of electricity would be important to allow market signals for flexibility to reach end-users. A stronger power transmission connection from the Nordics to the mainland-Europe and the United Kingdom would be beneficial for the emission reductions and renewable energy use. The transition pathway analysis points out socio-technical issues such as social acceptance of large-scale new infrastructures (e.g., wind, cables). The energy system optimizations indicate that most of the investments needed for the zero-emission pathway until 2050 would take place already by 2030.
\end{abstract}

Keywords: energy transition; decarbonization; sector coupling; policies; renewable energy

\section{Introduction}

Mitigation of climate change according to the Paris Climate Agreement from 2015 will require very strong measures and enforcing policies in the coming decades. The technological change required will be a major challenge as over $80 \%$ of all energy is still based on fossil fuels [1,2]. The recent report by the UN Intergovernmental Panel on Climate Change (IPCC) [3] has alerted politicians, businesses, and the public about the urgency of stricter policy measures to cut carbon emissions. In spite of the urgency to reduce $\mathrm{CO}_{2}$ emissions, the European Union has so far failed to find unanimity to commit to climate neutrality by 2050 [4]. 
Reaching carbon neutrality by 2050 will not only require a complete technological change in the ways energy is produced, but this will also encompass major societal changes, turning the clean energy transition into a major socio-technical transition [5]. The political measures in the transition also have a link to the sustainable development goals, two of which being directly linked to energy (SDG7, SDG13) [6].

Developing carbon-neutral pathways has received increasing interest as part of the general decarbonization quest ahead. The IPCC along with the International Energy Agency [1] has presented several deep-decarbonization scenarios, in all of which new and renewable technologies seem to play a central role along with energy efficiency measures to cut $\mathrm{CO}_{2}$ emissions. In some studies $100 \%$-renewable energy systems have been proposed [7-10]. Many cities aim at carbon neutrality before 2050 [11]. Country analyses on carbon neutrality are numerous [12]. Eighteen countries in the European Union have announced plans for carbon neutrality by 2050 [13], including large countries such as Germany and France, and there is growing momentum to decide on this goal at the EU level as previously skeptical countries like Hungary and Bulgaria are turning around [14].

Northern European countries, and in particular the so-called Nordic block (Denmark, Finland, Iceland, Norway, Sweden) have ambitious $\mathrm{CO}_{2}$ reduction targets and policies. The Nordic countries have issued a Nordic Carbon Neutrality declaration [15], which calls for carbon neutrality by 2050, and all Nordic countries have policies in place to reach carbon neutrality by year 2050, some countries even before that. For instance, the Government of Finland has just recently strengthened its climate-change mitigation policies by requiring full net carbon neutrality in the country by 2035 and becoming carbon negative by 2050 [16]. The Nordic region as a whole forms an interesting case for deep decarbonization pathways based on its present power mix, which is already almost carbon-free [17]. Over half of all electricity produced in the region is hydropower, which provides a major reserve for balancing power in case of large-scale variable renewable electricity (VRE) use. There is also a strong political will to reduce emissions, but also positive past experience in using energy markets as a tool to reach energy policy goals. Actually, the Nordic region was among the first to liberalize its electricity markets worldwide and to form a unified market region and electricity exchange in the 1990's, i.e., the Nord Pool power exchange [18], which has functioned as a pioneering example for many other regions and countries.

The Nordic region has major chances to reach carbon neutrality by 2050. The pathway to this goal has been analyzed in detail in the Nordic Flagship Project Flex4RES (Flexibility for Variable Renewable Energy Integration in the Nordic Energy Systems) [19], the results of which are discussed here. The aim of this paper is to depict cost-optimal pathways for the Nordic countries, including also the nearby Baltic states (Estonia, Latvia, Lithuania). The uniqueness of the present study is in viewing the energy system, markets, and policies as interlinked and holistically as a unity, contrary to previous analyses on the Nordic region [20]. Such a "whole-picture" view enables stronger coupling of markets across the sub-regions and sectors. Sector coupling is actually an enabler to a much higher use of variable renewable electricity such as wind power in the energy system because of increased energy system flexibility $[21,22]$. This is mainly because surplus electricity can easily be used in other sectors such as heating or transport, which further helps with the decarbonization quest. In particular, a power-to-heat (P2H) [21-24] strategy would be important in the northern context, as most of the final energy use is in the form of heating because of the cold climate.

This paper describes the main results from technical, economic, regulatory, and policy analyses combined with comprehensive energy scenario modelling to build a pathway to carbon neutrality in a cost-efficient and coherent way by year 2050. Actually, for the first time reported, this paper shows a pathway with the necessary policies to reach not only carbon neutrality (carbon sources = carbon sinks), but also zero carbon emissions from the heating and power sectors (carbon sources $=0$ ) in a much shorter time than anticipated before. An important pre-requisite for a fast and deep decarbonization is an increasing $\mathrm{CO}_{2}$ price. The present work goes beyond the state-of-the-art of traditional energy scenario studies [20] by placing the pathway into a socio-technical transition framework [25] analyzing 
some key social issues resulting from the transition. This kind of setting, in which the emissions drop fast but in a cost-efficient way and considering the societal side as well, is welcome considering the urgency to reverse global $\mathrm{CO}_{2}$ emissions.

The paper is organized as follows. First, the present energy and emission situation in the region is presented, followed by the method used in the analysis and the scenarios chosen for analysis. Then, the main results are presented followed by the conclusions.

\section{Starting Point of the Analyses}

Prior to the policy analyses, the starting point is shortly presented by introducing the energy and policy situation in the Nordic-Baltic region. In addition to the four Nordic countries (Iceland is part of the Nordics, but was excluded from the analysis as it is not part of the same market), the three Baltic states (Estonia, Latvia, Lithuania) were also included in the analysis as all seven belong to the Baltic Sea region and to the same electricity market (Nord Pool). The region is located in Northern Europe and the seven countries encompass some 30 million people. The Nordic region is characterized by high living standards (GDP $>\$ 45 \mathrm{k} / \mathrm{cap}$ ), stable policies, and good educational systems, among others.

\subsection{Energy and Emission Situation}

Energy plays an important role in the region because of the cold climate, long distances (low population density), large renewable energy resource (RES) base, and energy intensive industries. The present energy and $\mathrm{CO}_{2}$ emission situation in the region along with the EU and USA for comparison is shown in Table 1. The energy use in the Nordic-Baltic region represents $<8 \%$ and the emissions slightly over $4 \%$ of those of the whole European Union (EU), i.e., the energy mix is less carbon intensive than in the EU on average. Norway is not part of the European Union (EU-28) statistics. Norway is also a major energy exporter and it produces energy (oil, gas) which equals to over $15 \%$ of EU's primary energy demand. Estonia, Finland, Latvia, and Lithuania have energy-intensive economies above the EU average (0.09), even beyond that of the United States (0.13) [2]. Finland stands out in the region with the highest total carbon emissions, but Estonia has the most energy and carbon intensive economy.

Table 1. Present energy and emission situation in the Nordic-Baltic region (2016) [2,26,27].

\begin{tabular}{|c|c|c|c|c|c|c|}
\hline Country ${ }^{1}$ & $\begin{array}{l}\text { TPES } \\
\text { (Mtoe) }\end{array}$ & $\begin{array}{l}\text { Energy/GDP } \\
\text { (toe000/2010\$) }\end{array}$ & $\begin{array}{l}\text { Emissions } \\
\left(\mathrm{MtCO}_{2}\right)\end{array}$ & $\begin{array}{l}\text { Emissions } \\
\text { (tCO } / \text { cap) }\end{array}$ & $\begin{array}{c}\text { Emissions }{ }^{2} \\
\left(\mathrm{tCO}_{2} / \text { cap }\right)\end{array}$ & $\begin{array}{c}\text { RES Share } \\
(\%)^{3}\end{array}$ \\
\hline Denmark & 16.5 & 0.05 & 33.5 & 5.84 & 8.8 & 32.8 \\
\hline Finland & 34.0 & 0.13 & 45.5 & 8.28 & 10.9 & 34.7 \\
\hline Norway & 27.2 & 0.06 & 35.5 & 6.78 & 10.5 & 45.7 \\
\hline Sweden & 49.2 & 0.09 & 38.0 & 3.83 & 5.6 & 41.2 \\
\hline Estonia & 5.5 & 0.23 & 16.4 & 12.44 & 15.1 & 18.4 \\
\hline Latvia & 4.3 & 0.15 & 6.8 & 3.47 & 6.1 & 42.5 \\
\hline Lithuania & 7.2 & 0.16 & 10.8 & 3.75 & 7.3 & 21.2 \\
\hline EU-28 & 1586 & 0.09 & 3192 & 6.24 & 8.4 & 13.9 \\
\hline USA & 2167 & 0.13 & 4833 & 14.95 & n.a. & 11.0 \\
\hline
\end{tabular}

${ }^{1}$ Iceland is part of the Nordic region, but not part of the Nord Pool market; ${ }^{2}$ Man-made emissions of the "Kyoto basket" of greenhouse gases; ${ }^{3}$ RES—renewable energy sources, 2017 data; ${ }^{4}$ TPES—-total primary energy supply.

The Nordic-Baltic region is very strong in using renewable energy sources (RES) as shown in Table 1. The shares of RES are much beyond the EU-average; in Latvia, Norway, and Sweden even three times higher. This is explained by the large forest (bioenergy) and hydropower resources, but also increasing use of wind power as part of the power sector decarbonization. Actually, the role of renewables is emphasized in the electricity sector shown in Table 2, indicating that more than half of all electricity production is based on hydropower. Power production based on fossil fuels stands for only slightly over 10\%, less than a quarter of that in the EU. However, the use of new renewables (solar and wind) is well below the EU average, partly because of an already high RES intensity in power 
production and less need for new power generation capacity. But the largest relative wind power use in the EU is found in Denmark, which generates almost half of its electricity from wind power, having therefore ample experience in large-scale integration of VRE into the energy system [1]. The share of the electricity sector of the Nordic-Baltic region in the whole EU is $13 \%$, which is much more than its share of the EU primary energy $(<8 \%)$. This underlines the role of the region as a clean power producer for the whole EU.

Table 2. Electricity mix in the Nordic-Baltic region in 2016 (TWh) [17].

\begin{tabular}{cccccccc}
\hline Country & Fossil & Nuclear & Hydro & Biomass & VRE $^{\mathbf{1}}$ & Production & Consumption \\
\hline Denmark & 11 & 0 & 0 & 4.5 & 13.5 & 29 & 35 \\
Finland & 13.5 & 22.5 & 15.5 & 11 & 3 & 66 & 85 \\
Norway & 3 & 0 & 143 & 0 & 2 & 149 & 133 \\
Sweden & 3.5 & 60.5 & 61 & 10 & 15.5 & 152 & 140 \\
Estonia & 9 & 0 & 0 & 1 & 0.5 & 10.5 & 8.5 \\
Latvia & 3 & 0 & 2.5 & 1 & $0+$ & 6.5 & 7.5 \\
Lithuania & 1 & 0 & 0.5 & 0.5 & 1 & 4 & 41.5 \\
TOTAL & 44 & 83 & 223 & 27 & 36 & 416 & 219 \\
Share (\%) & 10.5 & 21.1 & 53.6 & 6.5 & 8.7 & & $2786(\mathrm{TWh})$ \\
EU-28 (\%) & 48.9 & 25.7 & 12.1 & (in fossil) & 13.4 & $3100(\mathrm{TWh})$ & \\
\hline
\end{tabular}

${ }^{1}$ VRE—variable renewable electricity, mainly wind power.

Considering the above situation, renewable energies and the power sector could play a major role for a clean energy transition, but energy efficiency measures would also be important because of the high energy intensities in several of the region's countries. The power sector in the Nordic-Baltic region is already almost $(\sim 90 \%)$ carbon free, and extending carbon-free electricity to other sectors such as heating and transportation could help decarbonizing the whole society.

\subsection{Policy Situation}

The Nordic-Baltic region belongs to the European Union (EU; Norway is part of the EEA-treaty), which also determines a common energy and climate policy framework to its Member States. The EU has defined its energy and climate policy goals by 2030 in the "Clean Energy for all Europeans" package as follows [28]:

- $40 \% \mathrm{CO}_{2}$ emission reduction;

- $32 \%$ renewable energy share;

- $32.5 \%$ energy efficiency target.

This policy package has legislative power and requires the Member States to draft 10-year national energy and climate plans for the period 2021-2030 including a long-term view up to 2050.

In addition, goals on economic growth and new jobs from green energy, and better power transmission interconnections between the Members States were stated, among others. For the EU power sector, a 50\% renewable electricity target is set by 2030 and fully carbon free by 2050 .

The renewable energy and emissions goals of the Nordic-Baltic region are given in Table 3, which show a much higher level of ambitions than in the EU on an average. A few countries (Finland, Sweden) have announced targets for net-emission carbon neutrality already before year 2050, but in general full carbon neutrality by 2050 could be a realistic goal for the region as a whole based on the present policy goals. Much of the deep decarbonization would be based on renewable energy use. 
Table 3. Renewable energy (RES) and $\mathrm{CO}_{2}$ reduction targets in the Nordic-Baltic region.

\begin{tabular}{ccc}
\hline Country & Share of RES & CO $_{\mathbf{2}}$ Target \\
\hline Denmark & $100 \%$ by $2050^{1}$ & Carbon neutrality by 2050 \\
Finland & $>50 \%$ by $2030^{1}$ & Carbon neutrality by 2035 \\
Norway & $67.5 \%$ by $2020^{1}$ & Carbon neutrality by 2050 \\
Sweden & $100 \%$ by $2040^{2}$ & Carbon neutrality by 2045 \\
Estonia & $42 \%$ by $2030^{1}$ & $-80 \%$ by 2050 \\
Latvia & $45 \%$ by $2030^{1}$ & $-80 \%$ by 2050 \\
Lithuania & $45 \%$ by $2030^{1}$ & $-80 \%$ by 2050 \\
\hline
\end{tabular}

${ }^{1}$ Of final energy; ${ }^{2}$ Of electricity.

\section{Methods}

Developing the pathway(s) for deep decarbonization in the Nordic-Baltic region leading to zero-emissions in the energy sectors (electricity, heating) by 2050 is based on the following elements:

(1) Defining a market-based scenario framework. In a market-based or market-orientated approach, the energy production volumes and prices are basically determined by the demand and supply of energy aiming at least-cost solutions, as opposed to a government-controlled approach in which public sector interventions could distort prices or lead to preferential solutions [29];

(2) Balmorel energy system model [30] for comprehensive energy system and energy market simulations to turn the scenarios into necessary energy system changes;

(3) Energy system flexibility as key strategy to enable large-scale variable renewable electricity used with emphasis on sector coupling;

(4) Identification of socio-technical implications, and defining further policy measures to realize the path to carbon-neutrality;

(5) Survey of regulatory and technical barriers against flexibility.

The core of the method and work is around techno-economic optimizations $(1,2,3)$, accompanied by socio-technical considerations (4) and policy analysis $(4,5)$. The multi-step approach is described in more detail below.

\subsection{Policy Scenarios}

There are several ways to frame the energy transition [31]. Framing of policies is important as it includes defining the factors against which the priorities are set, which in turn would also influence the solutions. Here, a market-based approach was chosen to identify the least-cost alternatives to decarbonize the energy sectors. It was therefore appropriate to reflect the necessary policies in terms of market-related factors which hamper or accelerate decarbonization. The main strategy to facilitate the zero-carbon energy transition was focusing on large-scale renewable energy schemes accompanied by sector coupling of energy markets across the Nordic-Baltic to increase the flexibility of the energy necessary to adopt variable renewable electricity at large scale.

The differentiation of the policy cases (scenarios) was consequently done along two dimensions, namely regulatory and technical barriers for increasing interconnections (with and without these) which could affect the mobilization of flexibility measures. This yielded four basic scenarios, explained in the following:

- (1) BAU: Business-as-usual (BAU) case resembling the Nordic Energy Technology Perspectives case [20] (2016) with the present regulatory framework in the Nordic-Baltic region;

- (2) Connect: As Scenario 1, but introducing more transboundary power transmission capacity to better interconnect the Nordics with the mainland-Europe (Belgium, France, Germany, Poland, the Netherlands) and the United Kingdom, which requires removing technical barriers for extended transmission capacity, but the regulatory barriers would still remain; 
- (3) Policy: As Scenario 1, but eliminating regulatory barriers that hamper power sector flexibility and sector coupling, the technical barriers would still remain;

- (4) Combi: As Scenario 2, but also eliminating regulatory barriers that hamper power sector flexibility and sector coupling, i.e., in this scenario both the technical and regulatory barriers would be eliminated.

The scenarios thus fall in the regulatory-technical barriers matrix as follows:

- BAU: high regulatory and high technical barriers;

- Connect: high regulatory and low technical barriers;

- Policy: low regulatory and high technical barriers;

- Combi: low regulatory and low technical barriers.

Connect and Combi scenarios represent the cases in which the Nordic energy market is also stronger coupled to the mainland Europe and to the United Kingdom to enable export of electricity and "flexibility", whereas in BAU and Policy scenarios the focus is on the intra-market in the Nordic-Baltic region only. Carbon-taxation is also a very important policy instrument to enforce lock-out from fossil fuel generation. It is assumed that the carbon-tax would increase during the 2020 's to $65 € / \mathrm{tCO} 2$ and double to $130 € / \mathrm{tCO} 2$ by 2050 , which is along the line of other international studies [1,20]. All scenarios lead to a zero-emission (techno-economic) target by 2050, their difference being in how to reach this target and how much it would cost. Importantly, the high $\mathrm{CO}_{2}$ price used is not enough to secure full carbon neutrality, but will require additional policy push to reach $\mathrm{CO}_{2}$ neutrality.

\subsection{Energy System Modelling}

The energy system modelling necessary for the policy analyses is done with the Balmorel energy model, which is a partial equilibrium model supporting modelling and analysis of the energy sectors with emphasis on the electricity and heating sectors [32]. Balmorel is an open source code employing the GAMS modelling language.

The model has a comprehensive geographical subdivision that allows identification of countries (for description of e.g., taxes, emissions, etc.), regions (for electricity transmission) and areas (for district heating systems, local cost elements, etc.). If considering a 1-year time horizon for the optimization, hourly segmentation would be appropriate, whereas long time-horizons such as here would be done with coarser time segmentation. An arbitrary number of heat and power production units can be included for which technical and economic parameters are given (e.g., rating, costs, efficiencies, etc.). All types of technologies can be modelled, also energy storage. Electricity transmission is modelled in detail, allowing identification of bottlenecks in the transmission system e.g., when introducing large scale VRE, but also to show the differences in electricity prices according to geography.

Balmorel is an optimization model assuming perfect competition. It solves a least-cost problem with boundary conditions and limitations in the same way as if it had been centrally planned [32,33]:

$$
\begin{gathered}
C(e, h)=\min \left[\sum_{i} C_{i}\left(e_{i}, h_{i}\right)\right] \\
e=\sum_{i} e_{i} ; h=\sum_{i} h_{i} ; g_{i}\left(e_{i}, h_{i}\right) \leq 0
\end{gathered}
$$

where $e=$ electricity, $h=$ heat, $C=$ costs, $g=$ a set of linear expressions; subscript $i$ stands for the production units.

The direct emissions from energy production plants are considered in the model, but the in-direct emissions originating e.g., from manufacturing of the energy technologies or their installation and maintenance were not considered.

The model has been documented in detail elsewhere (http://www.balmorel.com/) and it has been used extensively for country and regional analyses. The input data used in this analysis extends from 
2016 to 2050 and is mainly based on data from the Flex4RES project [19]. The current generation units form the starting point for the model analysis, where each technology has an assumed lifetime varying between 30 and 40 years. The model applies endogenous modelling of investments in new generation technologies, and in two of the four scenarios, transmission line investments are also endogenously determined in the model. All investment costs required to achieve the zero-emission pathway are accounted for in the scenarios. Fuel and carbon price assumptions are in line with the Nordic Energy Technology Perspectives report [20]. An hourly time resolution is used in the modelling, where 52 seasons with 24 representative hours are used for the optimization. The spatial modelling covers the Nordics (Finland, Sweden, Denmark, Norway) and the Baltics (Estonia, Latvia, Lithuania). In cases of linking the Nordics to the rest of the EU, the spatial scope is extended with mainland Europe countries (Germany, Poland, France, Belgium, the Netherlands) and the United Kingdom.

The resource base and potential of renewable energy sources depend on weather conditions, notably in case of wind power, solar energy, and hydropower. Representative reference data was used in the calculations for renewable energy, but year-to-year statistical variations were not considered. It should also be noticed that the climate change will affect the weather and hence also the renewable energy production, e.g., the wind and solar conditions and precipitation may change [34-36], but considering these effects were outside the scope of this paper.

\subsection{Flexibility Strategies}

Increasing energy system flexibility to allow large-scale integration of VRE in an optimal and cost-effective way is one of the key strategies employed in this study. The strategies to increase flexibility are numerous ranging from upward and downward flexibility to shifting flexibility. The available practical measures for flexibility are likewise numerous, their use often depending on the overall portfolio of flexibility, economics, and complementarity offered. Technology options offering increased energy system flexibility include energy storage [37], smart grids, flexible power plants, interconnections, P2X, among others. [38]. Measures leaning on market-mechanisms to increase flexibility include demand side management (DSM) and demand response, balancing agreements, time-based pricing, etc. $[39,40]$. In the Nordic context, the existing hydro-power schemes (53\% of all electricity) and the good transboundary connections have already provided a certain flexibility potential, but in addition, the potential of demand side management and response is considerable, or $15-30 \%$ of the peak power demand, which can be explained by the rather large share of household heating of all electricity $(23 \%)$ [17]. Though the industrial electricity use is high in the region $(40 \%)$, the potential contribution of industrial DSM is rather low (4-7\% of the peak demand) as much of the industries are process industries requiring steady and continuous running [17]. The potential of increasing supply side flexibility e.g., through expanding existing pumped hydro power schemes or harnessing still free-running rivers in the region (e.g., in Norway and Sweden), is limited because of the strict environmental legislation and local resistance of the population.

Power-to-X (P2X, X stands for final energy forms or services) constitutes a set of strategies in which the (surplus) power is coupled to other sectors such as heating $(\mathrm{P} 2 \mathrm{H})$ or transport (electric vehicle charging P2V) to provide a broader base to increase the system inertia [38]. Typically, electricity forms around a quarter of the final energy use, but most of the final energy needed in the northern latitudes is actually heat $(>50 \%)$. In this way e.g., $\mathrm{P} 2 \mathrm{H}$ coupling could absorb large amounts of surplus wind energy by using electric resistance heating or heat pump units [41]. If in this case the heating demand would not be adequate to absorb the surplus power, adding large-scale heat storage, which is much cheaper than electricity storage, would be an easy additional measure [23].

The main strategies for flexibility chosen here are sector coupling, in particular power-to-heat accompanied with heat storage, power transmission grid expansions, and existing hydro power as a fast-response supply-side measure. The analyses also included flexibility provided via demand response, flexible electric vehicle (EV) battery charging, and power-to-gas (P2G) solutions, but these options appeared to be less important in the Nordic context than the previously mentioned ones. 
It is assumed that extensive electrification of vehicles will take place in Europe by 2050, so that one-third to one-half of the car fleet in the Nordic-Baltic region would be electrified (plug-in EV and full EV) while in Norway the share would be $90 \%$. Assuming smart charging of EVs would add to the total pool of flexibility even without active vehicle-to-grid (V2G) use, e.g., when vehicles are charged during less costly or less system-stressed time periods [42]. If the rest of the car fleet and road transport were based on carbon free fuels such as biofuels, the whole transport sector could also become emission free by the middle of this century. However, as no profound transport system modelling was done, any far-reaching conclusions on the transport side will not be done here.

\subsection{Identification of Regulatory Barriers in Front of Flexibility}

Improved energy system flexibility is a measure needed to reach high shares of renewable energy. The European Union, which also affects the Nordic-Baltic region policies, promotes flexibility in electricity markets to ensure security of supply and affordability while fulfilling the goal of a high share of renewable energy in the EU Member States. New policy measures mentioned in EU's "Clean Energy for all Europeans" package from 2016 include obligations for market coupling, enhancing regional cooperation, developing intra-day and cross-border balancing markets, rolling out smart meters, and dynamic pricing [28].

Though the regulative role of the European and Nordic policies is recognized as central to the development in the energy sector, including energy system flexibility, an in-depth survey was done on regulatory barriers in the Nordic and Baltic market [43]. The main source for the analysis was four comprehensive reports from the Flex4RES project on framework conditions [44-47], EU, Nordic, and the national energy policies and strategies regarding energy systems and flexibility, and 15 in-depth interviews with stakeholders from the Nordic countries and organizations [48]. The survey highlighted areas which would require special attention from the policy makers, decision-makers, and key stakeholders. There are several barriers with varying importance, also varying by country, but two common barriers stand above all, namely (BA1) insufficient market signals for some stakeholders, and (BA2) uneven frameworks for different renewable energy resources. Several empirical observations support emphasizing these two barriers. First, policy and regulatory measures are largely decoupled from the electricity market prices, which affect different sectors on different levels and in various ways. For instance, some of the current support schemes to specific renewable energy sources (RES) are decoupled from the flexibility needs. Second, fiscal policies such as tax exemptions or subsidies often favour specific energy resources or technologies over others. This results in distortions in the market. For example, if biomass-based district heating $(\mathrm{DH})$ receives a tax exemption, this would likely increase the cost advantage of biomass-based units over power-to-heat (P2H) units. This kind of support could promote biomass heat-only boilers over flexible combined heat and power (CHP) and $\mathrm{P} 2 \mathrm{H}$, which in turn would decrease the sector coupling of heating and electricity.

Based on the barriers identified, we have formulated policy recommendations to unlock the flexibility potential. As the barriers (BA1, BA2) relate to inadequate market signals to some stakeholders, market design, and regulations, the policy recommendations need a strong link to the markets and modifications of the present support schemes. Seven policy recommendations (REC1-REC7) were identified, which positively respond to the barriers:

- REC1: Create a level playing field for RES across sectors through consistent fiscal policies (consistency within the countries accounting for combined effects of tariffs, taxes, subsidies, and externalities);

- REC2: Implement grid tariffs which allow market signals for flexibility to reach the end-users;

- REC3: Dynamic taxation of electricity (e.g., restructuring levies and taxes);

- REC4: Encourage VRE operators to act flexibly using short-term market-based incentives;

- REC5: Abolish RES support during negative electricity price periods;

- REC6: Enhance electrification by removing the limitations on using electricity for heating; 
- $\quad$ REC7: Tackle investment risks in flexible individual heating through new financing and private ownership models.

Table 4 shows the importance of each recommendation in the countries of the region, for which reason the recommendations need to be applied selectively accounting for the specific conditions of each country. Two recommendations (REC 2 and REC3) are common to the whole region and they clearly convey a policy message to focus on market-based policies. Revising tariffs, taxation schemes, and subsidy structures are of high priority in this context. For example, a more dynamic taxation or tariff system could increase the use of cheap demand side response [49]. Increasing $\mathrm{CO}_{2}$ taxes would encourage uptake of flexible renewable sources. Reforming outdated regulation prohibiting electrification of other sectors could enhance coupling of power, heat, transport, and gas, which would leapfrog the flexibility in the energy system as a whole. Improved flexibility opportunities are found across all levels in the energy system from producers, interconnectors (e.g., transmission system operators (TSO) and distribution system operators (DSO)), to consumers. However, capturing the flexibility potential would require providing a common level playing field as defined in the recommendations above to account for the differences among the market actors. Several of the other recommendations relate to this too $[50,51]$.

Table 4. Policy recommendations to remove barriers from flexibility in the Nordic-Baltic region [43].

\begin{tabular}{ccccccccc}
\hline Country & Recommendation $^{1}$ : & REC1 & REC2 & REC3 & REC4 & REC5 & REC6 & REC7 \\
\hline & Linked to barrier $^{2}$ : & BA2 & BA1 & BA1, 2 & BA1, 2 & BA1, 2 & BA2 & BA2 \\
\hline Denmark & & $X$ & $X$ & $X$ & $X$ & & $X$ & X \\
Finland & $X$ & $X$ & $X$ & & & & $X$ \\
Norway & & $X$ & $X$ & & & & $X$ \\
Sweden & & $X$ & $X$ & & $X$ & & $X$ \\
Estonia & $X$ & $X$ & $X$ & $X$ & $X$ & & \\
Latvia & & $X$ & $X$ & $X$ & & & \\
Lithuania & & $X$ & $X$ & $X$ & $X$ & $X$ & \\
\hline
\end{tabular}

${ }^{1}$ See text for the recommendations $1-7 ;{ }^{2}$ Key barriers: (BA1) insufficient market signals for some stakeholders, (BA2) uneven frameworks for different renewable energy resources.

Recommendations 1-7 form a market-based policy sub-framework for decision-makers, which could be used in a strategic context such as updating national climate-energy policies or in reforming policy measures to reflect on changing boundary conditions of the market such as price decrease and market growth of renewable electricity.

It should be observed that resolving the two barriers (BA1, BA2) through the recommendations in Table 4 does not automatically lead to zero emissions, but rather to unleashing the flexibility potential, which is a key enabler of an energy system change. The techno-economic optimizations with Balmorel model determine here the technical pathway to carbon neutrality.

\subsection{Socio-Technical Analysis Frame}

The energy system modelling outcomes are also analyzed in a socio-technical frame. The aim here is not to undertake a detailed in-depth analysis, but rather to identify broader issues that might emerge from the transition.

Established methods were used for the analysis including the following steps [5]: (1) Identification of socio-technical (ST) factors with potentially high effects on energy transition pathways; (2) qualitative assessment of these effects on the energy system; (3) quantitative assessment of selected ST factors using the Balmorel model; (4) analysis of implications for transition pathways (in terms of regulation, best practices, planning processes, etc.). One of the key social questions that needs attention is the social acceptance of large-scale energy schemes, e.g., the "NIMBY"-effects, but also possible distributional effects when markets change. 


\section{Results}

Next, the main results of this study are chronologically presented starting with the main scenario results (Scenarios 1-4), which also consider the market barriers, followed by a brief socio-technical analysis.

\subsection{Scenario Outcomes}

The evolution of the Nordic energy system toward zero-carbon emissions is described through the 4 scenarios described in Section 3 simulated with the Balmorel model to yield estimates on the quantitative changes in the energy system.

The Flex4RES-project findings on the barriers hampering flexibility (Table 4) suggest that the Policy and Combi scenarios require substantial regulatory changes to overcome the barriers. In addition, the countries differ in respect of the technology mix (Table 2), the need for flexibility, as well in the framework conditions at regional and local levels. Therefore, a holistic view is needed to target low-cost, high-potential sources of flexibility from other sectors or from different markets that can be released by removing specific barriers. In the Policy and Combi scenarios, the flexibility provided by the other sectors is facilitated by the redesigning of the regulations in the direction of a targeted and coherent framework aimed at transmitting the correct electricity price signals, for example, by redesigning grid tariffs. In doing so, a greater degree of electrification is made possible across sectors while ensuring that the electricity sector benefits from unlocked sources of flexibility. This, for instance, concerns the removal of sector-oriented policy mechanisms distorting the price signals from one energy source to another, with detrimental effects on electrification and subsequent flexibility from large consumers, including power-to- $X$, for example, and the redesign of incentive-based grid tariffs.

Figure 1 depicts the key results on the aggregated Nordic-Baltic electricity and heating sectors. The results are based on a least-cost optimization of the energy system, i.e., the results represent a cost minimum. The scenarios in Figure 1 have a similar underlying trend. Wind and hydropower will dominate the future electricity production in the region, but some bio-based CHP would also remain in power production as a well as a small fraction nuclear power (Finland).

The minor role of nuclear power in the future scenarios, considering that nuclear presently stands for more than $20 \%$ of all electricity in the region (see Table 2), is due to the past political decisions in the region to run the present nuclear power plants (NPPs) until the end of their life-time, but not building new capacity. In case of Finland, the future share of nuclear power plants may still be considerable ( $>25 \%$ of all electricity in 2050) because of policy decisions made in the early 2000's and 2010's to build more nuclear power (Olkiluoto 31600 MW and Fennovoima 1200 MW NPPs). The Finnish case represents a kind of lock-in effect as the life-time of new NPPs may extend up to 60 years. In case of Sweden, no decision for new NPPs have been done and the life-time of the present NPP fleet will expire well before the year 2050. NPPs also encounter major economic challenges because of high investment costs [52,53]. However, if political decisions in Finland and Sweden were made to extend the use of the present NPPs beyond 2050, though improbable, the use of the cheapest option (wind power) in the scenarios would decrease. The same applies in the political climate to build new NPPs change.

Solar photovoltaics is foreseen to grow after year 2030 and its share of the power capacity investments could approach $15-25 \%$ depending on the scenarios. All scenarios employed hourly profiles in the simulations, which in the case of solar photovoltaics (PV) is important, because of the high variability of solar radiation both on a diurnal and seasonal scale. Though the power share sounds quite substantial, the energy share of the PV of all electricity remains below $5 \%$ because of a low capacity factor of PV in northern Europe. Actually, producing PV electricity for local use in the region could be more cost-effective than importing PV electricity from the mainland Europe (scenarios Combi and Policy) with better solar radiation conditions, because imported electricity is subject to a substantial power transmission cost. The solar profile matches poorly the main energy demand in Northern Europe, which restricts its direct use. However, when accompanied with energy storage, e.g., with flexible hydro power, its usefulness increases to cover e.g., summertime uses for which diurnal 
storage is adequate [54]. At the same time, the wind power supply in the summertime typically drops as most of the wind resource concentrates to the autumn and winter months in the Nordic-Baltic region. As the Balmorel model only considers the bulk electricity market and is not able to handle the power distribution side, the PV is treated here as if it were a centralized option, while distributed PV closer to the end-users e.g., buildings was not considered.

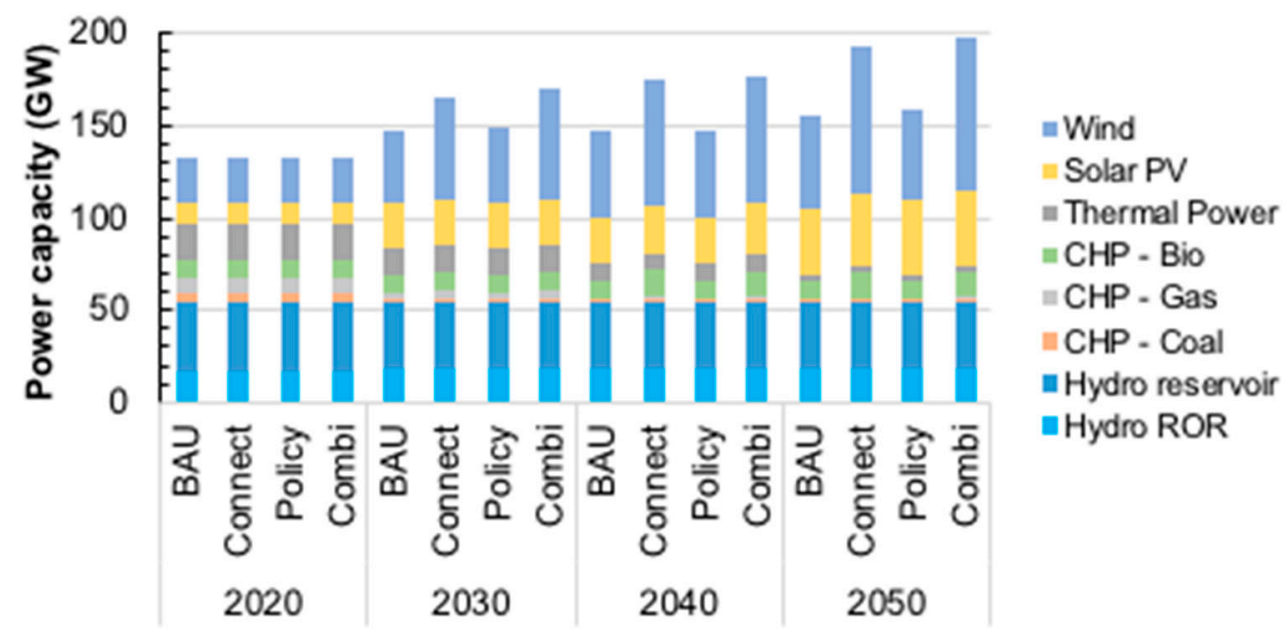

(a)

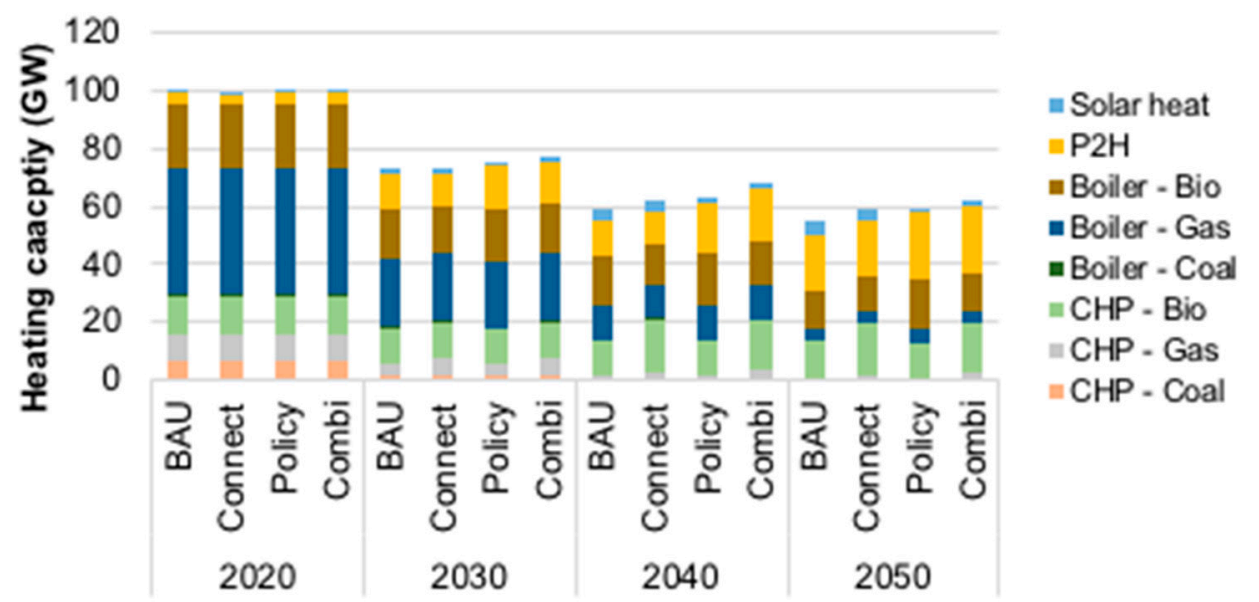

(b)

Figure 1. Energy system changes on aggregated Nordic-Baltic level in the scenarios from 2020 to 2050. (a) Power system changes; (b) Heat system changes. Scenarios 1-4 BAU (1): Business-as-usual; Connect (2): As SC1, plus more transmission capacity from the Nordics to mainland Europe and the United Kingdom, removing technical barriers; Policy (3): As SC1, but eliminating regulatory barriers; Combi (4): As SC2, but also eliminating regulatory barriers.

In heat production, $\mathrm{P} 2 \mathrm{H}$ and heat storage would stand for two-thirds of all heat and one-third would come from bio-based CHP in 2050. Heat storage would play an important role as a matching technology. Most of the heat storage demand would be short-term. Main energy system changes are already observed in the period 2020-2030 explained by the raising $\mathrm{CO}_{2}$ emission costs, but also because of new investment opportunities as existing capacities are approaching their end of life. The quick drop of the total $\mathrm{CO}_{2}$ emissions in the period 2020-2030 in Figure 2 well illustrates the rapid change. By year 2050, the emissions would in practice be at zero level in all scenarios. 


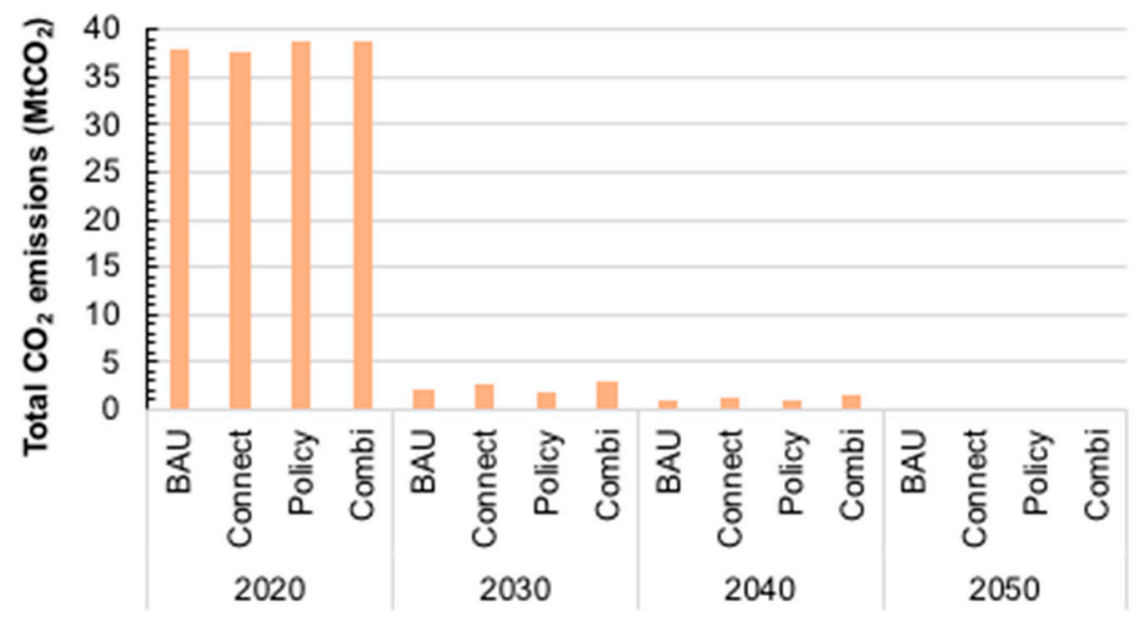

Figure 2. Total $\mathrm{CO}_{2}$ emissions of the Nordic-Baltic energy system (power and heat).

Stronger market coupling and removal of the regulatory market barriers lead to larger investments in renewable electricity, as demonstrated in Figure 1a, which depicts the power capacity development over time in the different scenarios. The business-as-usual case (BAU) remains at the lowest level, whereas the market coupling between the Nordics and the mainland Europe and United Kingdom (Connect and Combi) would lead to higher investments in transmission and renewable electricity technologies also servicing the non-Nordic market. This is because producing renewable electricity in the Nordics would be cheaper than in the mainland-Europe (e.g., France, Germany) and the United Kingdom. The removal of regulatory barriers (BAU vs. Policy or Connect vs. Combi) often enhances local flexibility and leads to higher renewable use, but also to $\mathrm{P} 2 \mathrm{H}$ utilization. Through better intra-Nordic power transmission capabilities (Policy, Connect, Combi), local flexibility improvements may also work the other way around by enabling better exchange of power between the Nordic countries, i.e., to "export flexibility" from one region to another, if necessary. The differences in the total investments in the electricity system is shown in Figure 3, demonstrating the higher investment profiles in Connect and Combi over BAU and Connect, when regulatory and technical barriers are removed. However, from year 2040 onward reduced investment levels are observed approaching those in the 2020's, or even below (BAU and Policy). This is explained by levelling out of price differences between the Nordics and mainland Europe and the United Kingdom, but also approaching zero-emission levels in own production which reduces the need of replacement investments of fossil-fuel plants.

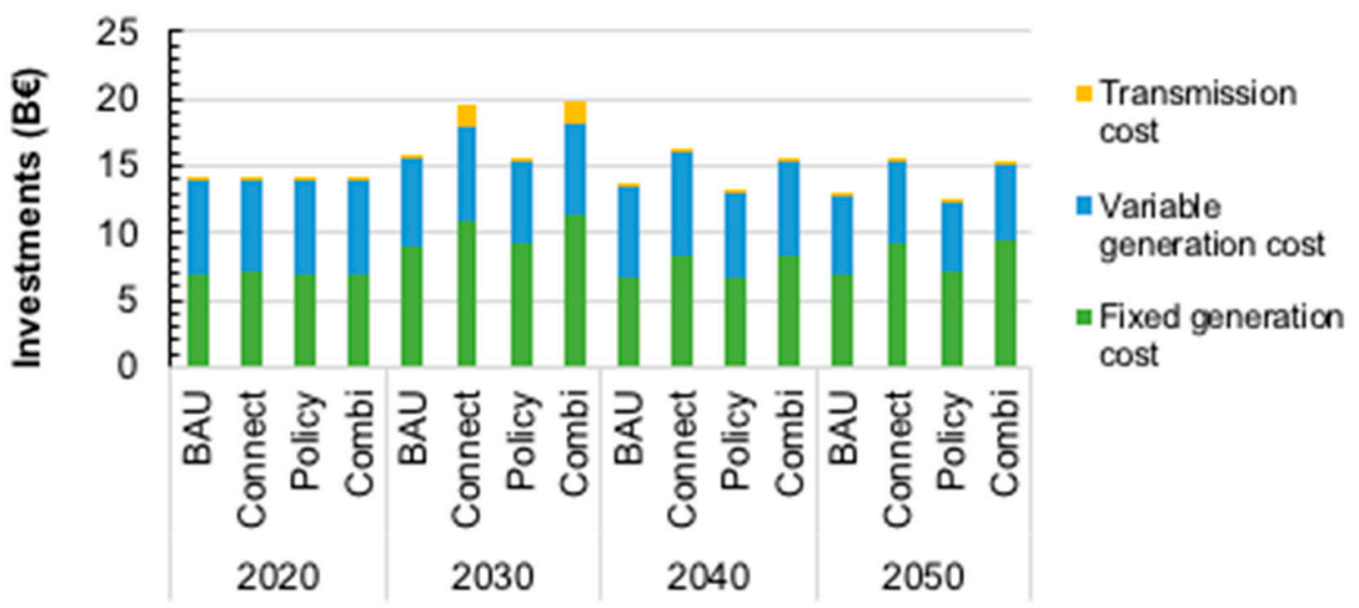

Figure 3. Investments in the electricity system (generation and transmission) in the scenarios during 2020-2050. 
Interestingly, none of the scenarios investigated here indicate the need of new electricity storage, i.e., batteries. Also, carbon capture and storage (CCS) technologies, which still encompass major uncertainties, would not be necessary to reach carbon neutrality in the energy sectors in the Nordic-Baltic region. Moving beyond year 2050, if it were necessary to move to negative emissions, the schemes presented here could be extended and linked e.g., to power-to-gas schemes (P2G), which employ electricity and carbon dioxide to produce synthetic gas [38]. Other options could then include CCS and natural carbon sinks (forests), among others. However, the beyond-2050 era options were not analyzed in the present study.

\subsection{Socio-Technical Issues}

There are important societal issues associated with decarbonizing the energy system, which are not necessarily captured by techno-economic energy system or optimization models [5] such as the Balmorel [32], which was used in this study. One key concern here is the distribution of costs and benefits associated with the energy transition, e.g., new energy technologies and infrastructures, among different groups in the society. An unfair distribution of costs and benefits could cause resistance to the energy transition and change its form, speed, and cost. Resistance can manifest itself as low social acceptance on local level, where new energy technologies are sited, or as opposition to wider systemic changes on national level, for example in relation to changes in electricity prices. Processes on these two levels can reinforce each other, e.g., national political debates reported in the media can fuel local resistance, and vice versa, and there can also be interactions with supra-national debates on Nordic, $\mathrm{EU}$, and global levels.

Regarding the local level, all the scenarios analyzed above involve large investments in variable renewable energy technologies (Figure 3), including significant deployment of onshore wind and solar, or of near shore wind. The Connect and Combi scenarios furthermore involve a significant expansion of the electricity grid. Past experiences with siting of especially onshore wind farms (e.g., in Denmark) and high-voltage transmission lines (e.g., in Norway), suggest that low social acceptance on local level could be an important potential barrier to the timely realization of zero-emission pathways, especially given the unprecedented scale and speed of deployment of these technologies in the scenarios.

Concerning resistance to wider systemic changes, Figure 4 depicts changes in producer revenues (bars) and consumer costs (line) in the scenarios during 2020-2050. Up to year 2040, the cost of electricity to consumers increases in the Combi and Connect scenarios, while the electricity producers experience an increase in revenues, especially the owners of hydropower, wind, and CHP. This change in the relative distribution of costs and benefits between these two societal groups is driven in large part by the expansion in electricity generation and transmission capacity to satisfy electricity demand outside the Nordic-Baltic region, where prices are higher during this period (see Section 4.1). A significant part of these investments is in onshore wind (due to its relatively low cost) and high-voltage transmission lines (needed to export power), both of which involve major landscape modifications as well as perceived health risks. Therefore, national-level opposition to ("unfair") increases in energy bills (e.g., by energy-intensive industries) could well co-evolve with local resistance to wind farms and high-voltage lines and pylons.

Consumer costs decrease again between 2040 and 2050 to previous levels, and the cost-revenue gap levels off, but this is a rather long waiting from a consumer perspective. Abandoning fossil fuels may also have severe social effects, e.g., job losses, in particular in oil and gas producing Norway, but also partly in Finland, where about $4 \%$ of the primary energy still originates from carbon-intensive peat. Similarly, there would also be feed-back effects into the local economy from increasing carbon-prices assumed in the scenarios. Altogether, a zero-emission transition in the Nordic-Baltic region may depend critically on the ability to manage and overcome socio-technical barriers at local to national scale during the 2020-2040 period, particularly regarding the distributional and governance aspects of renewable energy technologies and infrastructures. 


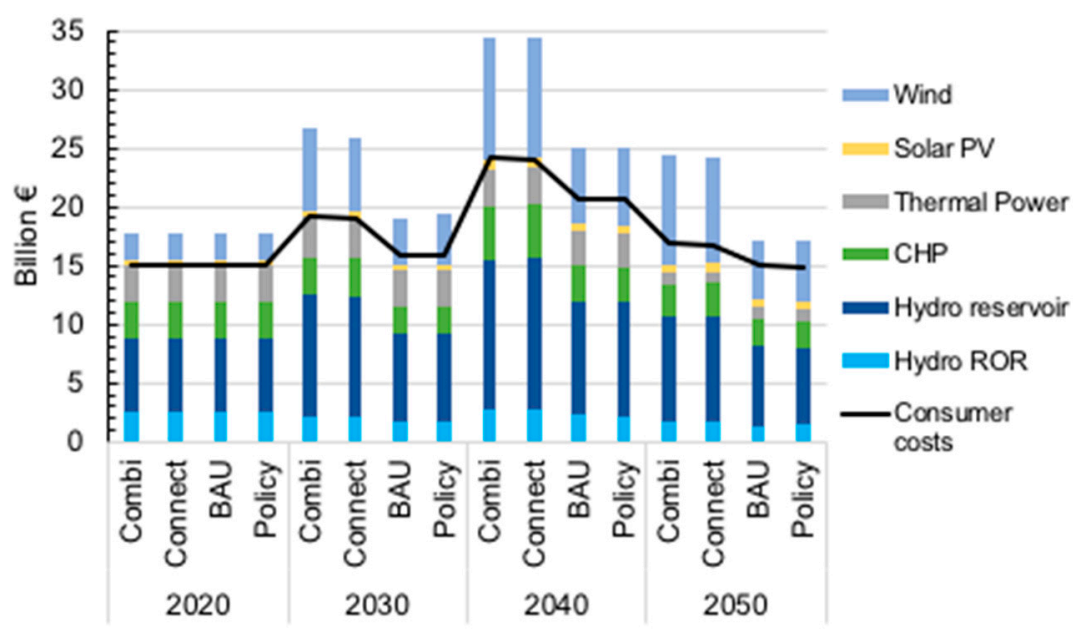

Figure 4. Value of electricity in the scenarios during 2020-2050 in terms of producer revenues (bars) and consumer costs (line).

\section{Formulating a Pathway toward Carbon-Free Energy Sector}

Energy is a complex system, which constitutes of networks, interactions, many actors, self-organized elements, etc. [55]. Describing changes in such a intertwined environment is highly challenging. The energy transition could be framed in different ways, leading to different prioritizations and different solutions [31].

The four scenarios showed the techno-economic changes in the Nordic energy sector to reach a carbon-free energy sector. However, such profound changes also need to be embedded in the social and political systems. Therefore, the pathway to zero-carbon was also placed in a socio-technical transition framework, meaning that the final energy transition will be influenced by the co-evolution of the techno-economic system, socio-technical issues, and policy actions [5]. All three "layers" need to match to ensure the required change.

The Flex4RES scenarios represent the techno-economic system, but they also include consideration of market design and policy actions. In addition, a socio-technical analysis was undertaken to analyze the role of non-technical factors such as social acceptance. These together constitute the Nordic pathway to zero-carbon, as depicted in Figure 5.

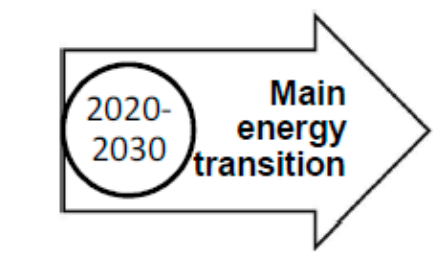

Nordic electricity sector decarbonized

Large deployment of wind Phase out of fossil fuels Regulatory barriers removed Business for flexible actors

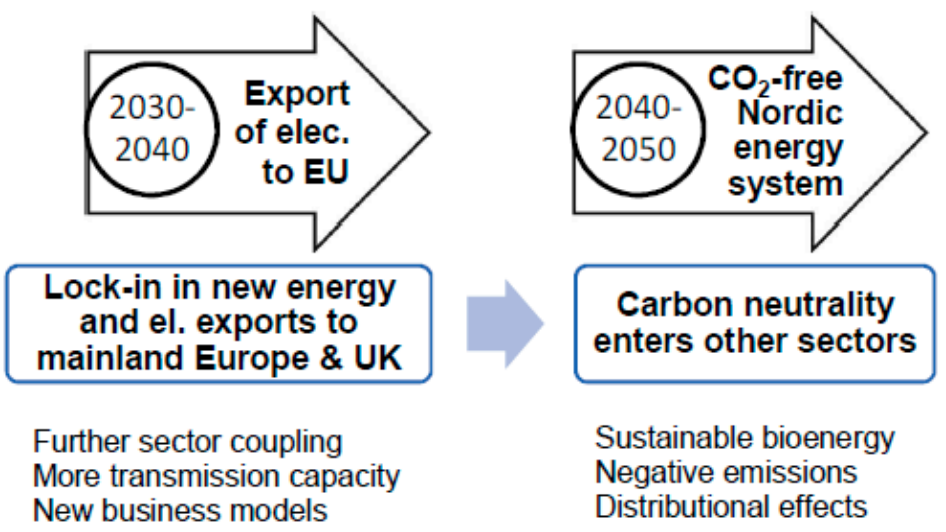

Figure 5. The Nordic-Baltic zero-emission pathway.

The zero-carbon pathway in Figure 5 has three distinctive phases up to 2050. The first phase called "energy transition" takes place in the 2020's featuring a sharp turn to clean energy requiring massive investments in new energy and infrastructure motivated by the steep increase in carbon price. 
The 2020's will be of critical importance for the whole zero-carbon transition in the Nordics as most of the changes required need to be put into place then to reach the goals in 2050. Basically, the regulatory and political framework must also to be reformed to remove key market and technical barriers in front of the new investments.

In particular, enabling a level playing field and technology neutrality in the investments, and proper signals such as dynamic tariffs or taxes to encourage flexibility measures are needed. Because of the high intensity of new technology investments such as on-shore wind power, important social acceptance, and behavioural consequences that could hamper the development may occur. This would require e.g., more careful siting and planning guidelines and R\&D efforts to develop alternative technologies further such as off-shore wind power, which may intervene less with the population. Similar social issues may later occur with new transmission lines or large solar PV production fields. The role of heat storage, which already now is applied extensively in distributed heating system and to some extent also in district heating (CHP) systems, will significantly grow as a balancing technology linked to P2H and may need further R\&D efforts to enable successful scaling-up.

The second phase in the 2030's called "export of electricity to EU" is characterized by a distinctive lock-in into renewable energy and flexibility technologies in the energy sector. Exports from the Nordics to the rest of the EU would increase once regulatory barriers for this are removed and new transboundary transmission line investments take place (scenarios Connect and Combi). This would generate much higher revenues to the Nordic power producers, but would also increase the consumer prices of electricity before settling back closer to the middle of the century. The consequent distributional effects will need consideration in the policies. The strong electrification of the energy sector through sector coupling may also raise new challenges on its resilience against different wicked problems such as cyber-security [12].

Basically all key elements for a carbon-free energy sector would need to have been put place in the 2020's and 2030's. The policies need to move even faster to enable optimal framework conditions: The Nordic-Baltic region has to focus already in the 2020's on sector coupling and market approaches, remove regulatory barriers, and allow business cases for flexibility actors.

The last period in the 2040 's called " $\mathrm{CO}_{2}$-free Nordic energy system" would take the final steps to ensure a fully sustainable energy sector. The sector coupling has further been strengthened to enable high shares of renewable energy leading to higher electrification of the heating sector through P2H and less biomass use, which could instead be used for biofuels in the transport sector and other green chemicals. The adoption of the "new technologies" reaches its maximum by 2050 . There are indications that after year 2050 negative emissions may be necessary to limit the global temperature rise to $1.5^{\circ} \mathrm{C}$, which may need introduction of a range of other measures such as electrification of industrial processes, power-to-gas, CCS, among others, not considered in the timeframe 2020-2050. The export of electricity from the Nordic countries to the mainland-Europe and the United Kingdom will also start to fade as the price differences even out in this period. Though not analyzed in detail here, energy efficiency and utilization of waste heat may deserve future attention because of the large potential involved.

\section{Discussion and Conclusions}

From the above analyses, a set of important observations, conclusions, and recommendations can be drawn.

Table 4 and the scenario results in Section 4 indicate the need for regulatory changes to remove barriers to enhance flexibility. Coherent changes to market designs, regulatory framework conditions, and coupling of markets are needed. For example, improvements to the regulatory frameworks of heat, gas, transport, and electricity sectors that can supply flexibility are needed along with the growth of VRE in the electricity supply in order to develop coherent Nordic energy markets. This will require smart market designs and framework conditions implemented in a timely fashion. Otherwise, 
integrating energy markets with very different framework conditions (e.g., heat vs. electricity) may prevent the transition towards integrated energy systems and increased flexibility.

So far, the energy policies in most Nordic and Baltic countries have been too focused on the traditional policy framework dominated not only by environmental issues, but also by considerations of security and cost of supply, while lacking awareness of energy system flexibility. However, flexibility has recently received more attention in the Nordic area. In a high-level report from the Nordic Council [56], the need for greater flexibility is emphasized as a necessary aspect of increasing the share of VRE in the region. This paper adds to this report by reviewing some of the challenges involved and by drawing up possible scenarios for what this future might look like and where Nordic energy co-operation should be targeted.

The common electricity market (Nord-Pool) is an example of successful Nordic energy co-operation, whereas in the heat, gas, and transport sectors national policies and regulations have dominated. This has created differentiated and more complex policy arrangements that challenge the future coordination of the decarbonization and electrification of these sectors.

There are many good reasons to strengthen energy co-operation through the introduction of focused and coherent policies. The main questions are where to set the focus and how much effort is needed? Should the focus be on cooperation in the existing electricity market, trusting that the market can cope with the flexibility challenges indicated by the future energy system with a large share of variable renewable energy? Should the Nordic co-operation be strengthened over electricity by reforming the existing market design and adding more transmission capacity between the Nordic countries? Or should one explore flexibility options that can be realized by introducing stronger connections between sectors through enhanced electrification of the heat, transport, and gas sectors? These different policy areas require different regulatory changes and the removal of barriers in order to be realized.

Table 4 highlighted the Nordic-Baltic differences. Setting up policy recommendations for a region of different countries therefore implies a more complex, but also a more robust policy focus, based on cooperation. The approach and scenarios analysis in this paper fits this purpose.

In line with the above discussion and the pathway depicted in Section 5, the following policy-related conclusions can be drawn:

1. $\mathrm{CO}_{2}$-free energy sector is possible, but Nordic and Baltic countries need to act fast in decarbonization:

The results unambiguously indicate that a $\mathrm{CO}_{2}$-free, least-cost, and reliable energy sector can be reached in the Nordic-Baltic region. Deep decarbonization of both the electricity and heating sectors are possible. Postponing investments in clean energy would require even steeper and costlier emissions cuts in the coming years and it would mean losing a unique window of opportunities which is opening up in terms of new investments and revenue creation in the coming decade. In practice, the main energy transition must be geared up already in the 2020's.

2. Nordics may play an important role in decarbonizing the EU and beyond:

The Nordic-Baltic region would benefit from acquiring a first mover and pioneering position worldwide.

The Flex4RES scenarios in Section 4 linking the Nordic-Baltic region and the mainland-European and UK energy systems indicate that exporting $\mathrm{CO}_{2}$-free electricity could be good business to the Nordic utilities. The Nordics could through a flexible energy system also provide more flexibility to the rest of the EU helping in the European energy transition. The expected revenues of electricity exports could be in the range of $€ 5-10$ billion a year in the period 2030-2040 (Figure 3).

3. Nordic cooperation enables more efficient solutions allowing differences:

The results clearly show the benefits for regional collaboration and acting together for finding solutions. The Nordic solutions shown are inclusive drawing upon national characteristics. For example the Norwegian/Swedish hydropower and Danish/Finnish/Baltic district heating provides much flexibility, and the Danish/Swedish wind power build-up cheap renewable energy, of which 
the whole region benefits. Therefore, a harmonized policy set-up is not a pre-requisite to reach zero-emissions, though coherence is required.

4. A market-based approach enables market coupling for higher flexibility:

The advantages of combining different energy markets in the Nordic-Baltic region are evident. Emphasizing a market-based approach with the right coupling of the power market to the underlying national and local markets for heat, gas, and transport could generate enough cheap flexibility to successfully integrate large amounts of wind (and solar) power. Together with the removal of regulatory barriers it creates the necessary signals to the market actors to invest in and operate flexibility and go for smart sector coupling of energy systems (e.g., P2H). The flexibility opportunities are ample once the right incentives are in place and these could even cross national borders.

5. Technologies are mature for the energy transition:

The transition to a zero-carbon energy sector in the Nordics can be based on already well-proven and cost-efficient energy technologies, which minimizes risks and uncertainties associated with the energy change. This could therefore represent a more realistic future option for decision-makers in the region. The depicted transition leans strongly on the electrification of energy sectors (sector coupling), notably heating (power-to-heat, $\mathrm{P} 2 \mathrm{H}$ ), but also to some extent the transport sector. $\mathrm{P} 2 \mathrm{H}$ means in practice electric boilers and heat pumps, which are already in large-scale use in the Nordic countries. Heat storage, which is a cheap and proven way to store energy, would be utilized on a much larger scale than presently and linked to P2H. Long-term storage solutions would gradually be needed, which may need R\&D efforts to reduce technology uncertainties. Fossil-fuel power and heat supply would fade off by 2050, also supported by present national energy and climate policy targets. The focus of the power and heat supply would shift to existing hydro and wind power, supplemented by bioenergy-based combined heat and power.

6. Socio-technical questions deserve early attention:

A socio-technical analysis of the techno-economic energy transition pathway identified large-scale wind power, transmission grids, and distributional effects as areas in which complementary policy actions may be necessary to account for the social side of the transition. For example, if construction of wind power on-shore were less acceptable for local population this may require moving to more costly off-shore conditions which in turn may affect the cost-optimal energy system solutions shown in the scenarios. Similarly, other socio-technical transition factors such as lock-in, path dependencies or jobs, which were beyond the present study, may need more consideration in energy transition policies [5]. Policy measures necessary to overcome these barriers may include taxation, income transfers, increased $R \& D$, regional transitional support schemes, consideration of behavioral aspects, among others. These measures need to be fitted locally case by case, as the local conditions vary much across the region. But an important conclusion is that a zero-emission energy transition requires concurrent coevolution of techno-economic and socio-technical systems, and policies [3].

Though this study was limited to one major region in Europe only, many of the findings and conclusions may also apply to other regions as well. Importantly, a market-based integrative approach to deep decarbonization could play an important role in this context.

Author Contributions: P.D.L. was responsible for main part of the writing and guiding the writing process. K.S., C.B., S.B., and A.K. contributed to the policy and social transition analysis. T.F.B., J.G.K., H.K., and P.A.G. were responsible for the Balmoral simulations. D.B., A.G., L.S. contributed to commenting and background analysis. All authors contributed to reviewing of the manuscript.

Funding: This work was supported by the Nordic Energy Research (project Flex4RES, grant number 76084). P.D.L. also acknowledges the Research Council at the Academy of Finland (project WISE, grant number 312626).

Conflicts of Interest: The authors declare no conflict of interest. 


\section{References}

1. International Energy Agency (IEA). World Energy Outlook 2018; International Energy Agency: Paris, France, 2018. [CrossRef]

2. International Energy Agency (IEA). Key World Energy Statistics 2018; International Energy Agency: Paris, France, 2018. [CrossRef]

3. Masson-Delmotte, V.P.; Zhai, H.-O.; Pörtner, D.; Roberts, J.; Skea, P.R.; Shukla, A.; Pirani, W.; Moufouma-Okia, C.; Péan, R.; Pidcock, S.; et al. Global Warming of $1.5^{\circ} \mathrm{C}$. An IPCC Special Report on the Impacts of Global Warming of $1.5^{\circ} \mathrm{C}$ above Pre-Industrial Levels and Related Global Greenhouse Gas Emission Pathways, in the Context of Strengthening the Global Response to the Threat of Climate Change; Intergovernmental Panel on Climate Change: Geneva, Switzerland, 2018; Available online: https://www.ipcc.ch (accessed on 23 January 2019).

4. Tamma, P. EU leaders fail to commit to climate neutrality by 2050. Politico. 20 June 2019. Available online: https://www.carbonbrief.org/daily-brief/eu-leaders-fail-to-commit-to-climate-neutrality-by-2050 (accessed on 25 June 2019).

5. Bolwig, S.; Bazbauers, G.; Klitkou, A.; Lund, P.D.; Blumberga, A.; Blumberga, D. Review of modelling energy transitions pathways with application to energy system flexibility. Renew. Sustain. Energy Rev. 2019, 101, 1-23. [CrossRef]

6. United Nations SDG. Sustainable Development Goals. Available online: https://sustainabledevelopment.un. org/?menu=1300 (accessed on 23 June 2019).

7. Jacobson, M.Z.; Delucchi, M.A.; Bauer, Z.A.F.; Goodman, S.C.; Chapman, W.E.; Cameron, M.A.; Bozonnat, C.; Chobadi, L.; Clonts, H.A.; Enevoldsen, P.; et al. 100\% Clean and Renewable Wind, Water, and Sunlight All-Sector Energy Roadmaps for 139 Countries of the World. Joule 2017, 1, 108-121. [CrossRef]

8. Jacobson, M.Z.; Delucchi, M.A.; Cameron, M.A.; Frew, B.A. Low-cost solution to the grid reliability problem with $100 \%$ penetration of intermittent wind, water, and solar for all purposes. Proc. Natl. Acad. Sci. USA 2015. [CrossRef] [PubMed]

9. Becker, S.; Frew, B.A.; Andresen, G.B.; Zeyer, T.; Schramm, S.; Greiner, M.; Jacobson, M.Z. Features of a fully renewable US electricity system: Optimized mixes of wind and solar PV and transmission grid extensions. Energy 2014, 72, 443-458. [CrossRef]

10. Barbosa, L.S.N.S.; Bogdanov, D.; Vainikka, P.; Breyer, C. Hydro, wind and solar power as a base for a $100 \%$ renewable energy supply for South and Central America. PLoS ONE 2017, 12, e0173820. [CrossRef] [PubMed]

11. C40 Cities Climate Leadership Group. Cities Leading the Way: Seven Climate Action Plans to Deliver on the Paris Agreement; C40 Cities Climate Leadership Group: London, UK, 2019.

12. Pilpola, S.; Arabzadeh, V.; Mikkola, J.; Lund, P.; Pilpola, S.; Arabzadeh, V.; Mikkola, J.; Lund, P.D. Analyzing National and Local Pathways to Carbon-Neutrality from Technology, Emissions, and Resilience Perspectives-Case of Finland. Energies 2019, 12, 949. [CrossRef]

13. Morgan, S. 18 EU Countries Now Support 2050 Carbon Neutrality Goal. Available online: https://www.euractiv. com/section/climate-strategy-2050/news/18-eu-countries-sign-up-to-2050-carbon-neutrality-goal/ (accessed on 23 June 2019).

14. Tamma, P.; Oroschakoff, K. Momentum grows for EU effort to set 2050 climate neutrality goal. Politico. 20 June 2019. Available online: https://www.carbonbrief.org/daily-brief/momentum-grows-for-eu-effort-to-set2050-climate-neutrality-goal (accessed on 20 August 2019).

15. Prime Minister's Office Finland. Declaration on Nordic Carbon Neutrality. Available online: https: //www.ym.fi/download/noname/\%7B5CF4258D-8264-4F5C-8527-081CCBBF2AE2\%7D/143425 (accessed on 23 June 2019).

16. Morgan, S. Finland pledges carbon neutrality on eve of EU presidency. Euroactiv. 5 June 2019. Available online: https:/www.euractiv.com/section/climate-environment/news/finland-pledges-carbon-neutralityon-eve-of-eu-presidency/ (accessed on 25 June 2019).

17. Söder, L.; Lund, P.D.; Koduvere, H.; Bolkesjø, T.F.; Rossebø, G.H.; Rosenlund-Soysal, E.; Skytte, K.; Katz, J.; Blumberga, D. A review of demand side flexibility potential in Northern Europe. Renew. Sustain. Energy Rev. 2018, 91, 654-664. [CrossRef]

18. Nord Pool AS. Bidding Areas. Available online: https://www.nordpoolgroup.com/the-power-market/ Bidding-areas/ (accessed on 20 June 2019). 
19. Nordic Energy Research. Flex4RES—Flexibility for Variable Renewable Energy Integration in the Nordic Energy Systems. Available online: https://www.nordicenergy.org/flagship/flex4res/ (accessed on 22 June 2019).

20. IEA; Nordic Energy Research. Nordic Energy Technology Perspectives 2016; International Energy Agency: Paris, France, 2016.

21. Arabzadeh, V.; Pilpola, S.; Lund, P.D. Coupling Variable Renewable Electricity Production to the Heating Sector through Curtailment and Power-to-Heat Strategies for Accelerated Emission Reduction. Future Cities Environ. 2019, 5, 1-10. [CrossRef]

22. Pilpola, S.; Lund, P.D. Effect of major policy disruptions in energy system transition: Case Finland. Energy Policy 2018, 116, 323-336. [CrossRef]

23. Lund, P. Large-scale urban renewable electricity schemes-Integration and interfacing aspects. Energy Convers. Manag. 2012, 63, 162-172. [CrossRef]

24. Kirkerud, J.G.; Bolkesjø, T.F.; Trømborg, E. Power-to-heat as a flexibility measure for integration of renewable energy. Energy 2017, 128, 776-784. [CrossRef]

25. Cherp, A.; Vinichenko, V.; Jewell, J.; Brutschin, E.; Sovacool, B. Integrating techno-economic, socio-technical and political perspectives on national energy transitions: A meta-theoretical framework. Energy Res. Soc. Sci. 2018, 37, 175-190. [CrossRef]

26. International Energy Agency. World Energy Balances 2018; International Energy Agency: Paris, France, 2019; Available online: http://wds.iea.org/wds/pdf/WORLDBAL_Documentation.pdf (accessed on 20 June 2019).

27. European Commission. Renewable Energy Progress Report; COM (2019) 225 Final; European Commission: Brussels, Belgium, 2019; pp. 1-16.

28. European Commission. Clean Energy for All Europeans; European Commission: Brussels, Belgium, 2017.

29. Cambridge Dictionary. Available online: https://dictionary.cambridge.org (accessed on 20 August 2019).

30. Karlsson, K.; Meibom, P. Optimal investment paths for future renewable based energy systems-Using the optimisation model Balmorel. Int. J. Hydrogen Energy 2008, 33, 1777-1787. [CrossRef]

31. Yun, S.-J.; Byrne, J.; Baker, L.; Bond, P.; Kaufmann, G.; Luhmann, H.-J.; Lund, P.; Martinez-Alier, J.; Yang, F. Energy and Climate Change. In Rethinking Environmentalism: Linking Justice, Sustainability, and Diversity; Lele, S., Brondizio, E.S., Byrne, J., Mace, G.M., Martinez-Alier, J., Eds.; MIT Press: Cambridge, UK, 2018; Volume 23, ISBN 1807-5932.

32. Wiese, F.; Bramstoft, R.; Koduvere, H.; Pizarro Alonso, A.; Balyk, O.; Kirkerud, J.G.; Ravn, H. Balmorel open source energy system model. Energy Strategy Rev. 2018, 20, 26-34. [CrossRef]

33. Ravn, H. The Balmorel Model: The Theoretical Background. 2001, pp. 1-29. Available online: http://www.balmorel.com/images/downloads/the-balmorel-model-theoretical-background.pdf (accessed on 20 August 2019).

34. Moemken, J.; Reyers, M.; Feldmann, H.; Pinto, J.G. Future Changes of Wind Speed and Wind Energy Potentials in EURO-CORDEX Ensemble Simulations. J. Geophys. Res. Atmos. 2018, 123, 6373-6389. [CrossRef]

35. Jerez, S.; Tobin, I.; Vautard, R.; Montávez, J.P.; López-Romero, J.M.; Thais, F.; Bartok, B.; Christensen, O.B.; Colette, A.; Déqué, M.; et al. The impact of climate change on photovoltaic power generation in Europe. Nat. Commun. 2015, 6, 10014. [CrossRef] [PubMed]

36. Solaun, K.; Cerdá, E. The impact of climate change on the generation of hydroelectric power-a case study in southern Spain. Energies 2017, 10, 1343. [CrossRef]

37. McPherson, M.; Tahseen, S. Deploying storage assets to facilitate variable renewable energy integration: The impacts of grid flexibility, renewable penetration, and market structure. Energy 2018, 145, 856-870. [CrossRef]

38. Lund, P.D.; Lindgren, J.; Mikkola, J.; Salpakari, J. Review of energy system flexibility measures to enable high levels of variable renewable electricity. Renew. Sustain. Energy Rev. 2015, 45, 785-807. [CrossRef]

39. European Commission DG Energy. Impact Assessment Study on Downstream Flexibility, Price Flexibility, Demand Response E Smart Metering; European Commission: Brussels, Belgium, 2016; Available online: https://ec.europa.eu/ energy/sites/ener/files/documents/demand_response_ia_study_final_report_12-08-2016.pdf (accessed on 20 June 2019).

40. Gravelsins, A.; Bazbauers, G.; Blumberga, A. Modelling energy production flexibility: System dynamics approach. Energy Procedia 2018, 147, 503-509. [CrossRef]

41. Pilpola, S.; Lund, P.D. Different flexibility options for better system integration of wind power. Energy Strategy Rev. 2019, 26, 100368. [CrossRef] 
42. Gunkel, P.A.; Fausto, F.J.; Skytte, K.; Bergaentzlé, C. The impact of EV charging schemes on the Nordic energy system. In Proceedings of the 16th European Energy Market Conference (EEM 2019), Ljubljana, Slovenia, 18-20 September 2019.

43. Lund, P.D.; Karimi, F.; Skytte, K.; Bergaentzlé, C. Better Policies Accelerate Clean Energy Transition; Nordic Energy Research: Oslo, Norway, 2018.

44. Bergaentzlé, C.; Boscán, L.R.; Skytte, K.; Emilie, R.S.; Olsen, O.J. Framework Conditions for Flexibility in the Electricity Sector. 2016. Available online: http://www.nordicenergy.org/publications/framework-conditions-for-flexibilityframework-conditions-for-flexibility-in-the-nordic-and-baltic-countries (accessed on 20 June 2019).

45. Sneum, D.M.; Sandberg, E.; Soysal, E.R.; Skytte, K.; Olesen, O.J. Flexibility in the District Heating-Electricity Interface; Nordic Energy Research: Oslo, Norway, 2016; Available online: http://www.nordicenergy.org/ publications/framework-conditions-for-flexibility-in-the-district-heating-electricity-interface/ (accessed on 20 August 2019).

46. Sneum, D.M.; Blumberga, D.; Katz, J.; Olsen, O.J. Framework Conditions for Flexibility in the Individual Heating-Electricity Interface; Nordic Energy Research: Oslo, Norwary, 2017; Available online: https://www.nordicenergy.org/publications/framework-conditions-for-flexibility-in-the-individualheating-electricity-interface/ (accessed on 20 August 2019).

47. Boscán, L.; Soysal, E.R. Framework Conditions for Flexibility in the Gas-Electricity Interface of Nordic and Baltic Countries; Nordic Energy Research: Oslo, Norway, 2017; Available online: https://www.nordicenergy.org/publications/framework-conditions-for-flexibility-in-the-gas-electricityinterface-of-nordic-and-baltic-countries/ (accessed on 20 August 2019).

48. Karimi, F.; Lund, P.D. Background Document to the Policy Brief: Better Policies Acclerate Clean Energy Transition-Focus on Energy System Flexibility; Aalto University: Espoo, Finland, 2018; Available online: https://www.nordicenergy.org/publications/better-policies-accelerate-clean-energy-transition/ (accessed on 20 August 2019).

49. Bergaentzlé, C.; Jensen, I.G.; Skytte, K.; Olsen, O.J. Electricity grid tariffs as a tool for flexible energy systems: A Danish case study. Energy Policy 2019, 126, 12-21. [CrossRef]

50. Sneum, D.M.; Sandberg, E. Economic incentives for flexible district heating in the nordic countries. Int. J. Sustain. Energy Plan. Manag. 2018, 16, 27-44.

51. Sneum, D.M.; Koduvere, H.; Olsen, O.J.; Blumberga, D. Policy incentives for flexible district heating in the Baltic countries. Util Policy 2018, 51, 61-72. [CrossRef]

52. Wealer, B.; Bauer, S.; Göke, L.; von Hirschhausen, C.; Kemfert, C. DIW Weekly Report 30/2019; DIW: Berlin, Germany, 2019.

53. Haas, R.; Mez, L.; Ajanovic, A. The Technological and Economic Future of Nuclear Power; Springer International Publishing: Basel, Switzerland, 2019; ISBN 978-3-658-25987-7.

54. Lund, P.D. Capacity matching of storage to PV in a global frame with different loads profiles. J. Energy Storage 2018, 18, 218-228. [CrossRef]

55. Bale, C.S.E.; Varga, L.; Foxon, T.J. Energy and complexity: New ways forward. Appl. Energy 2015, 138, 150-159. [CrossRef]

56. Ollila, J. Nordic Energy Co-operation: Strong Today-Stronger Tomorrow; Nordic Council of Ministers: Copenhagen, Denmark, 2017.

(C) 2019 by the authors. Licensee MDPI, Basel, Switzerland. This article is an open access article distributed under the terms and conditions of the Creative Commons Attribution (CC BY) license (http://creativecommons.org/licenses/by/4.0/). 